\title{
Citrullus colocynthis fruit extract as an anti-depressant in mice
}

Saeed Nafisi ${ }^{1}$, Leila Rezazadeh ${ }^{2 *}$, Ehsan Hosseini ${ }^{3}$, Morteza Shamsi ${ }^{4}$, Anwar Bahrami Mousavi $^{4}$, Ali Mohammad Bahrami ${ }^{5}$

1. Department of Physiology, Faculty of Veterinary, Urmia University, Urmia, Iran

2. Student Research Committee, Faculty of Nutrition and Food Sciences, Tabriz University of Medical Sciences, Tabriz, Iran

3. Department of Physiology, Faculty of Para Veterinary, Ilam University, Ilam, Iran

4. Department of Parasitology, Faculty of Medicine, Ilam University of Medical Sciences, Ilam, Iran

5. Department of Pathobiology, Faculty of Para Veterinary, Ilam University, Ilam, Iran

*Corresponding author:Tel: +98 9141852506 Fax: +98 44133251336

Address: Student Research Committee, Faculty of Nutrition and Food Sciences, Tabriz University of Medical Sciences, Tabriz, Iran

E-mail: Rezazadehleila@yahoo.com

Received: 2016/03/3 revised: 2016/04/11accepted: 2016/05/4

\section{Abstract}

Introduction: Depression has multifactorial characters including brain-behavioral disorders, alteration in cognitive psychomotor and emotional process. Millions of people are worldwide suffering from this illness. This disease happens in all ages of men and women. This research tries to introduce a traditional medication in comparison with common chemical antidepressant drugs. This experiment was designed to evaluate probably the antidepressant effect of Citrullus colocynthis fruit extraction.

Materials and methods: Thirty-two male mice (Balb/c) was randomly divided to four groups ( $\mathrm{n}=8$ each). Animals adapted and treated to diazepam, imipramine, aqueous and hydro alcoholic extract of Citrullus colocynthis fruit. All administrations were done via intraperitoneal $0.2 \mathrm{ml} /$ animal. Plant material after grinding was extracted with ethanol and evaporated under reduced pressure. Tail suspension test was carried out to assay the antidepressant effect of plant extraction in animals. The test was carried on before, and as well as 30, 60 and 120 minutes after injections.

Results: Our data indicated that after intraperitoneal administration of aqueous and ethanol extract, immobility duration exhibits statistically significant increase compared to agitation phase in all times after injection $(\mathrm{P}<0.05)$. Ethanol extract reduced statistically agitation time in 30, 60 and 120 min after injection compared to imipramine. Both aqueous and ethanol extract elevated immobility in minute $60(\mathrm{P}<0.5)$.

Conclusion: The present study suggested that Citrullus colocynthis extract could possess potential antidepressant and sedative effects which would be of therapeutic interest for using in the treatment of patients with depressive disorders. We suggest more research in this regard.

Keywords: Anti-depressant, Citrullus colocynthis, Herb, Mice

\section{Introduction}

Depression has multifactorial character including brain-behavioral disorders, alteration in the cognitive, psychomotor and emotional process. Millions of the people are worldwide suffering from this illness. This disease happens in all ages of men and women.

Depression is among leading disease burden universal and is estimated to show an escalating inclination in next century 
(1). This disorder is accompanying with a marked individual social and financial morbidity, harm of functioning and productivity and creates major demands on service providers in terms of work capacity (2). In recent decades, researchers are looking for chemical drugs such as antidepressants to treat depressive disorders. A complex issue about antidepressants is the increased danger for suicidality (3). In 2007 the Food and Drug Administration licensed a complete report about the rate of suicidality in the terms of treatment of this disease with numerous antidepressants (4). Furthermore, these drugs commonly cause gastrointestinal adverse effects, sleeplessness, headache, nervousness and sexual disorders $(5,6)$.

In the recent years, there is a more trend for using medicinal plants. One of the important herbs traditional medicines is Cucurbitaceae family; Citrullus colocynthis is a branch belonging to this class, this plant grows in sandy lands like Khozestan, Systan and Balochestan provinces this plant commonly can be found in Mediterranean and tropical environment. Citrullus extraction use as a traditional herbs medicine from a century ago, the mature and immature fruit of this plant has been used as an antiinflammatory and edema medicine by some researcher like Belsem Marzouk and his coworker in Rat (7).

Khatibi and his coworker (8), conduct a research experimental work on aqueous extracts of this plant as a anticandidal screening and antibacterial effect on gram positive and gram negative bacteria like E. Coli , Staphylococcus, P. Aeruginosa, E. Focalis in Khuzestan province of Iran, extraction of this plant has been used for the various Candida spp such as Candida glabrata, C. albicans, C. parapsilosis and C. kreusei, hole parts of this plant extraction showed very strong activity against all strains of candida spp.

Anti-oxidant activity of this plant extraction has been studied by researchers like Saba et al (9). This plant has been experimentally used for diabetic mice and positive effect has been reported (9).

Belsem Marzouk and his colleague (7) study the main chemical contains fruit of this plant and they reported that this fruit contains bitter test, resin (Colocynthein) and pectin gum. The seed of this plant contain a fixed oil amount $(17 \%)$ and albuminiods (6\%). Agarwal and his coresearcher study the effect root of $\mathrm{C}$. colocynthis plant extraction on diabetic rats. They reported the reduction of diabetes mellitus after three days used of this extraction (10).

There are several other reports of antidiabetic activity of this herb (11) anticancer (12) anti-fertility (13) effects of the fruit of this plant in rats and human.

In the present study, we investigated the anti-depressant effect of Citrullus colocynthis in male mice.

\section{Materials and methods}

The Collection of plant material: Citrullus colocynthis fruits were collected in autumn from the desert region of Ahwaz state in southeast of Iran. The plant was botanically identified in the department of biology at Urmia University (Iran). A voucher specimen of the plant is deposited in the herbarium of the laboratory. The ripe fruits were shade dried at room temperature.

Preparation of extracts of Citrullus colocynthis fruit: The Fruits of Citrullus colocynthis were air dried at room temperature $\left(20^{\circ} \mathrm{c}\right)$, oven dried (Gallenkamp hotbox oven, England) at $40^{\circ} \mathrm{c}$, pulverized and stored in air tight container. About 300 and $400 \mathrm{~g}$ of the Fruits of Citrullus colocynthis was macerated in 3000 and $3500 \mathrm{ml}$ of ethanol (absolute), respectively and stirred for 10 min for five consecutive days at room temperature. The plant materials fruit of Citrullus colocynthis were filtered using filter paper and the extract was concentrated using a water bath and a rotary evaporator (Buchirotavapor R110) at $75^{\circ} \mathrm{c}$. 
Animals and experiments: Thirty-two healthy mice $(\mathrm{Balb} / \mathrm{c})$ weighing between 50 to $70 \mathrm{~g}$ were selected for the present study. They were raised and housed in an air-conditioned animal room at $24 \pm 2^{\circ} \mathrm{c}$ and subjected to $12 \mathrm{~h} \mathrm{light/dark} \mathrm{cycle.} \mathrm{They}$ were allowed free access to feed pellet diet and tap water ad libitum. Mice was randomly divided to four groups $(n=8$ each). Animals adapted to diazepam treated $(20 \mathrm{mg} / \mathrm{kg})$, imipramine-treated $(20 \mathrm{mg} / \mathrm{kg})$, aqueous extract and hydroalcoholic extract of fruit. All administrations were done via intraperitoneal $0.2 \mathrm{ml} /$ animal $(100 \mathrm{mg} / \mathrm{kg})$. Tail suspension test was carried out to assay anti-depressant effect of Citrullus colocynthis in male mice. The test was done before the injections and as well as 30, 60 and 120 minutes after injections.

\section{Statistical analysis}

Normality of the data distribution was checked and confirmed. ANOVA test was applied to comparing multi groups and followed by Duncan post hoc by SPSS Microsoft (version 16). Significance of differences was assessed by 95 percent of confident and data were reported as mean $\pm \mathrm{SD}$. The $\mathrm{P}<0.05$ was considered as a statistical difference.

\section{Results}

In imipramine group immobility and agitation time in mice did not show statistical difference after 30min and 60 min after injection but immobility increase after $120 \mathrm{~min}$ statistically (Figure 1). In diazepam group after injection immediately immobility increases statistically in all recorded periods (Figure 2). After intraperitoneal administration of aqueous and ethanol extract of Citrullus colocynthis immobility duration exhibits statistically significant rising compared to agitation phase in all time after injection (Figure 3). Comparison of agitation time among groups revealed that ethanol extract of Citrullus colocynthis fruit is statistically potent and decrease agitation time in 30, 60 and 120 min after injection compared to imipramine group (Figure 4), but in this respect, aqueous extract is statistically effective in 30, $60 \mathrm{~min}$ after injection (Figure 3). Evaluation of immobility time declared that both aqueous and ethanol extract elevate immobility in $60(\mathrm{P}<0.5)$ and $120 \mathrm{~min}$ after injection compared to imipramine but this increase is not significant in minute 120 (Figure 5).

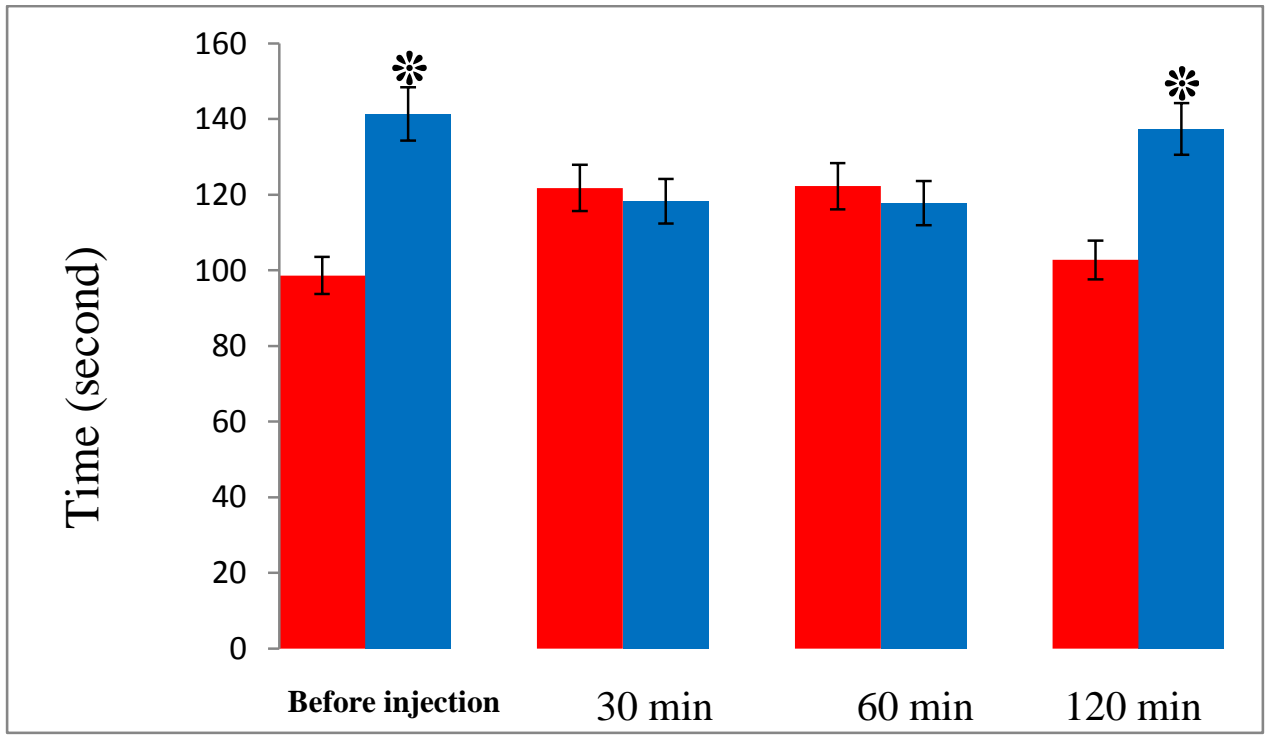

Figure 1. Immobility and agitation time in mice peritoneally injected imipramine.

*Represent statistically difference between two column attached together $(\mathrm{P}<0.05)$. 


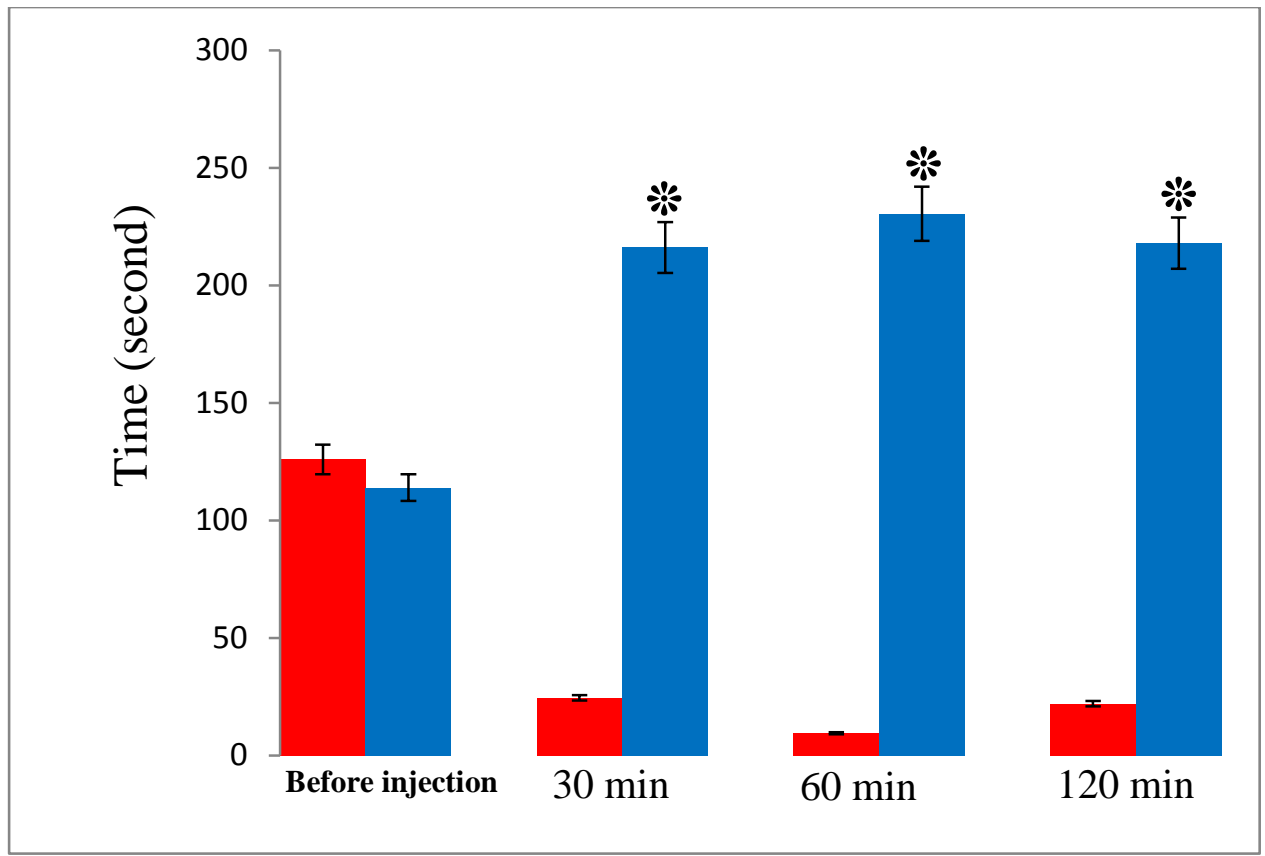

Figure 2. Immobility and agitation time in mice peritoneally injected diazepam.

*Represent statistically difference between two column attached together $(\mathrm{P}<0.05)$.
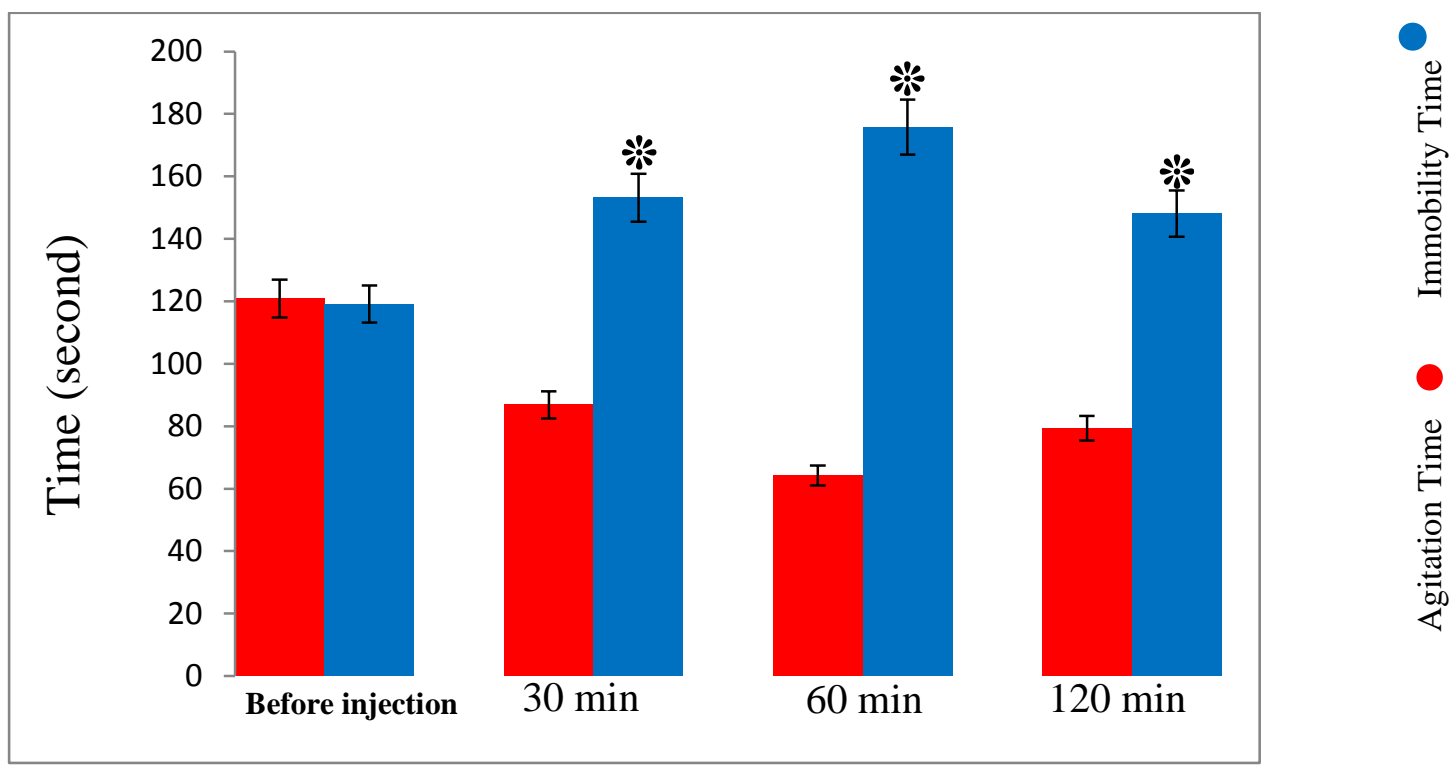

Figure 3. Immobility and agitation time in mice peritoneally injected aqueous extract of Citrullus colocynthis. $*$ Represent statistically difference between two columns attached together $(\mathrm{P}<0.05)$. 


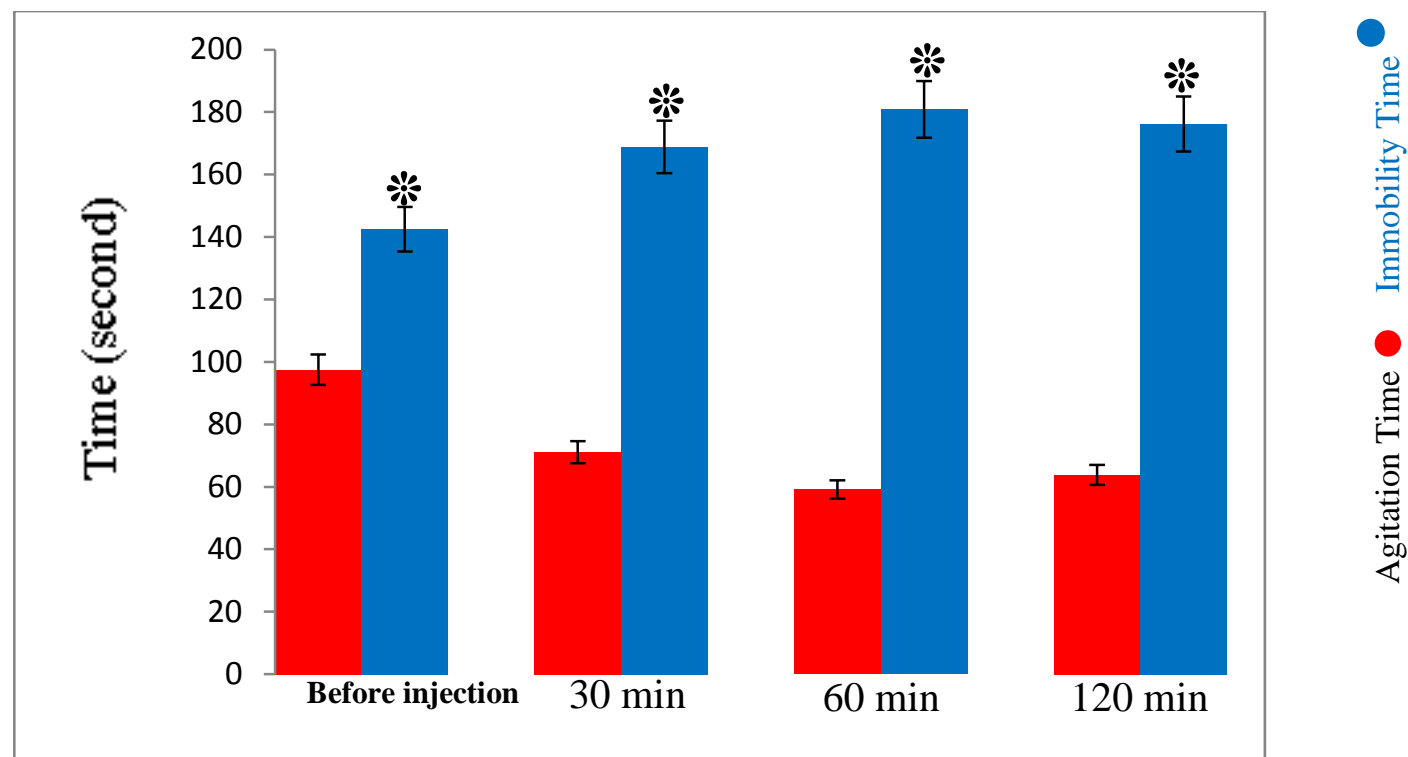

Figure 4. Immobility and agitation time in mice peritoneally injected ethanol extract of Citrullus colocynthis. *Represent statistically difference between two column attached together $(\mathrm{P}<0.05)$.

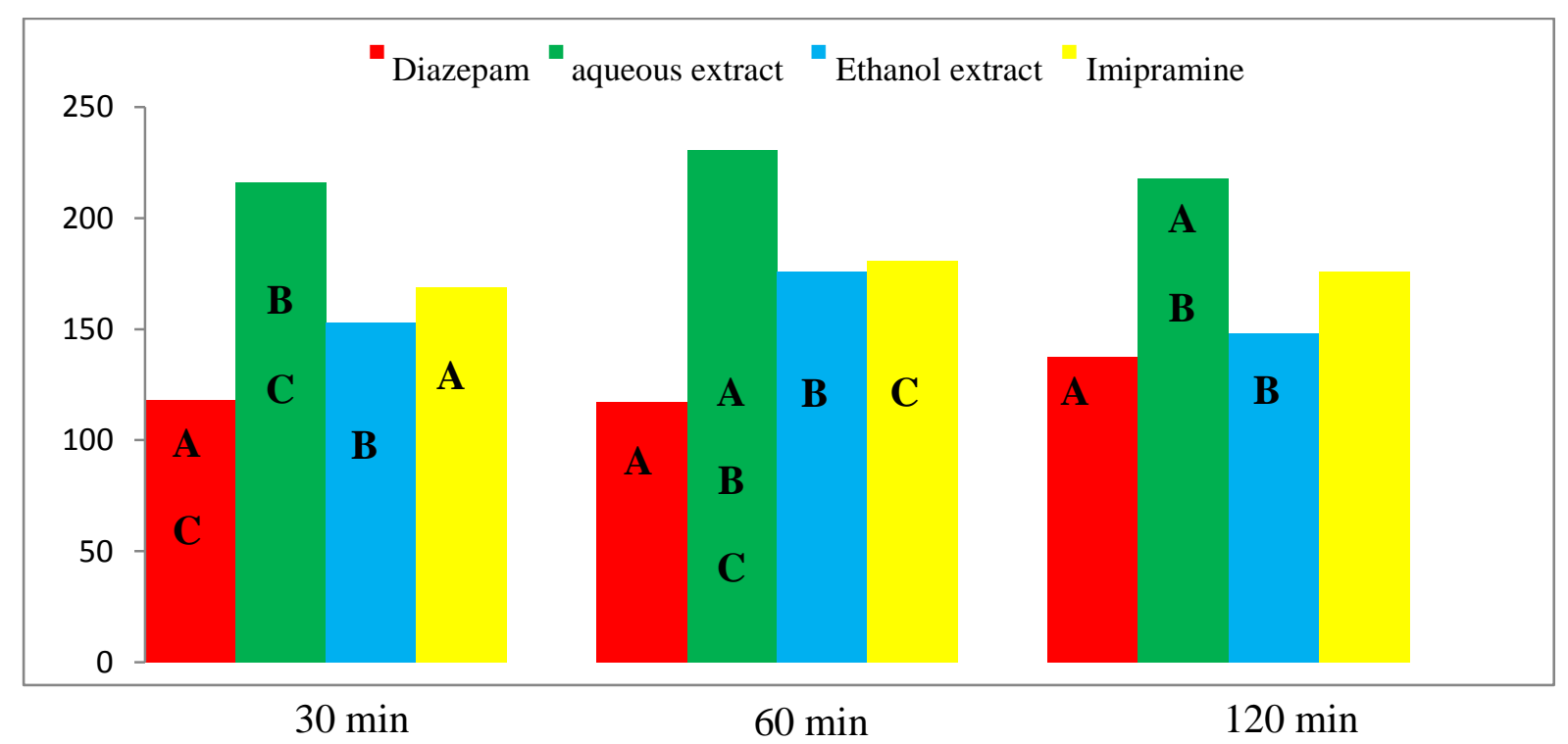

Figure 5. Immobility time (minute) in all treatment groups. Common letters indicate statistical differences columns attached together $(\mathrm{P}<0.05)$.

\section{Discussion}

For the first time, we found the antidepression effect of Citrullus colocynthis fruit extraction. Our study is in accordance with Adnaik R (2014) that reported the seeds extraction of fruit had antidepressant effect in $200 \mathrm{mg} / \mathrm{kg}$ with one difference that our findings was in $100 \mathrm{mg} / \mathrm{kg}$ dosage (14). Sultan Asyaz identified that fruit of Citrullus colocynthis has a significant amount of Saponins, Flavonoids, Alkaloids, Phenolic content as well as Riboflavin, Thiamine and Ascorbic 
acids (15). Zheng and et al indicated that Flavonoids extracted from plants had a considerable anti-depressant effect (16). This finding is consonant with Xiong $\mathrm{Z}$ and et al spotted extracellular signalregulated kinases cascade of antidepressant effect of Flavonoids (17). Antidepressant effect of Flavonoids also approved by Fan $\mathrm{ZZ}$ et al and Meizhu Zheng et al $(18,19)$. Furthermore, the antidepressant effect of Alkaloids was advocated by several studies (20,21 and 22). Antidepressant-like effects of Phenolic compounds are asserted by Messaoudi M and et al (23). There is also researches indicating anti-depressant effect of Saponins $(24,25)$. All these studies approved that anti-depressant effect of Citrullus Colocynthis can be justified by Flavonoids, Alkaloids, Phenolic and Saponins content of Citrullus colocynthis. The present study showed Citrullus colocynthis has some sedative effects of diazepam, the special agonist of GABAA receptors. Flavonoids as one of the major effective chemical compounds of Citrullus Colocynthis, have demonstrated

\section{References}

1. Whitty P, Gilbody S. NICE, but will they help people with depression? The new national institute for clinical excellence depression guidelines. Br J Psychiatry. 2005;186(2):177-8.

2. Kendrick T, Peveler R. Guidelines for the management of depression: NICE work? Br J Psychiatry. 2010;197(5):345-7.

3. Cipriani A, Geddes JR, Barbui C. Venlafaxine for major depression. BMJ. 2007;334(7587):215-6.

4. Friedman RA, Leon AC. Expanding the black box depression antidepressants and the risk of suicide. N Engl $\mathrm{J}$ Med. 2007;356(23):2343-6.

5. Goldstein BJ, Goodnick PJ. Selective serotonin reuptake inhibitors in the treatment of affective disorders-III. Tolerability, safety and pharmacoeconomics. J Psychopharmacol. 1998;12(4): 55-87.

6. Ferguson JM. SSRI antidepressant medications adverse effects and anxiolytic, sedative and anticonvulsant activities. Although their actions in the central nervous system occur through a variety of interactions with different receptors and signaling pathways, it is believed that some of these effects are mediated by ionotropic GABA. In particular, GABAA receptors (26). Therefore, the sedative effect of Citrullus colocynthis, saw in our study may be inconsistent with agonistic properties of flavonoids. Overall, we indicate a sedative effect of Citrullus colocynthis fruit. In comparison with anti-depressant imipramine and benzodiazepine anti-stress agent, diazepam .

\section{Conclusion}

In conclusion, the present study suggested that Citrullus colocynthis fruit extract possesses potential antidepressant and sedative effects which could be of therapeutic interest for using in the treatment of patients with depressive disorders. We suggested more study by the researchers in this regards.

tolerability. Prim Care Comp J Clin Psychiatry. 2001;3(6):22.

7. .Belsem M, Zohra M, Ehsen H, Manel T, Abderrahman B, Mahjoub A, Nadia F. Anti-inflammatory evaluation of immature fruit and seed aqueous extracts from several populations of Tunisian Citrullus colocynthis schrad. African J Biotechnol. 2011; 10(20):4217-25.

8. Rasool $\mathrm{K}$ and Jahanbakhsh T. Anticandidal screening and antibacterial of Citrullus colocynthis in South East of Iran. J Horticulture Forestry. 2011; 3(13):392-8.

9. Saba AB and, Oridupa AO. Search for a novel antioxidant anti-inflammatory/ analgesic or anti-proliferative drug Cucurbitacins hold the ace. J Med Plants Res. 2010; 4(25): 2821-6.

10. Agarwal V, Sharma AK, Upadhyay A, Singh $G$ and Gupta R. Hypoglycemic effects of Citrullus colocynthis roots. Acta Pol Pharm. 2012;69(1):75-9. 
11. Huseini HF, Darvishzadeh F, Heshmat R, Jafariazar Z, Raza M, Larijani B. The clinical investigation of Citrullus colocynthis (L.) schrad fruit in treatment of Type II diabetic patients a randomized double blind placebocontrolled clinical trial. Phytother Res.2009; 23(8):1186-9.

12. Grossman S, Dovrat S, Gottlieb HE, Bergman M. Growth inhibitory activity of cucurbitacin glucosides isolated from Citrullus colocynthis on human breast cancer cells. Biochem Pharmacol. 2007; 73(1):56-67.

13. Chaturvedi M, Mali PC and Ansari AS. Induction of reversible antifertility with a crude ethanol extracts of Citrullus colocynthis Schrad fruit in male rats. Pharmacol. 2003; 68(1):38-48.

14. Adnaik R S, Gavarkar PS, Mohite SK, Magdum CS. Anti-depressant activity of ethanolic extract of Citrullus vulgaris seeds in experimentally induced depressed mice. Res J Pharm Technol. 2014; 7(6);660-2.

15. Sultan A, Fullahkhan I, Hussain MA, Ullahkhan I. Evaluation of chemical analysis profile of Citrullus colocynthis growing in southern areas of Pakistan. World Appl Sci J 2010;10(4): 402-5.

16. Zheng M, Fan Y, Shi D, Liu C. Antidepressant like effect of flavonoids extracted from Apocynum venetum leaves on brain monoamine levels and dopaminergic system. Ethnopharmacol.2013 2;147(1):108-13.

17. Xiong Z, Jiang B, Wu PF, Tian J, Shi LL, $\mathrm{Gu} \mathrm{J}$, et al. Anti-depressant effects of a plant derived flavonoid baicalein involving extracellular signal regulated kinases cascade. Biol Pharm Bull. 2011; 34(2):253-9.

18. Fan ZZ, Zhao WH, Guo J, Cheng RF, Zhao JY, Yang WD, et al. Antidepressant activities of flavonoids from Glycyrrhiza uralensis and its neurogenesis protective effect in rats. Yao Xue Xue Bao. 2012; 47(12):1612-7.
19. Meizhu Z, Yajun F, Dongfang SH, Chunming L. Anti-depressant-like effect of flavonoids extracted from Apocynum venetum leaves on brain monoamine levels and dopaminergic system. $\mathbf{J}$ Ethnopharmacol. 2013 147(1): 108-13.

20. Cicero F, Trajano J, Oliveira LE, Alexandre J, Esdras D, Rocha E, et al. Piplartine an amide alkaloid from Piper tuberculatum, presents anxiolytic and anti-depressant effects in mice. Phytomedicine. 2007;14(9):605-12.

21. Martinez M, Estrada R, Araujo AG, Ledesma I, Martinez L, Moreno J, et al. Antidepressant-like effects of an alkaloid extract of the aerial parts of Annona cherimolia in mice. J Ethnopharmacol. 2012 ; 139(1):164-70.

22. Ubaldo SD, Araujo EA, Ledesma VI, Estrada R, Gonzalez EA, Martinez M. Anti-depressant effect of an alkaloid extract from Annona cherimolia. Planta Med. 2008; 15(9):74-82.

23. Messaoudi M, Bisson JF, Nejdi A, Rozan $\mathrm{P}$, Javelot H. Anti-depressant-like effects of a cocoa polyphenolic extract in Wistar Unilever rats. Nutr Neurosci. 2008; 11(6):269-76.

24. Lufan LI, Jie LU, Xiumin LI, Changliang XU, Jie Y, Rong QU, et al. Antidepressant-like effects of the saponins extracted from Chaihu jia longgu muli tang in a rat unpredictable chronic mild stress model. Fitoterapia. 2012;83(1): 93-103.

25. Haixia D , Ying C, Xinmin L, Wang Q, et al. Anti-depressant effects of ginseng total saponins in the forced swimming test and chronic mild stress models of depression. Neuropsychopharmacol Biol Psychiatry. 2009; 33(8): 1417-24.

26. Hanrahan J, Chebib M, Johnston G. Flavonoid modulation of GABAA receptors. $\mathrm{Br} \quad \mathrm{J}$ Pharmacol. 2011; 163(2):234-45. 